Dokuz Eylül Üniversitesi-Mühendislik Fakültesi

Fen ve Mühendislik Dergisi

Cilt 20, Sayı 59, Mayıs, 2018
Dokuz Eylul University-Faculty of Engineering Journal of Science and Engineering Volume 20, Issue 59, May, 2018

DOI: $10.21205 /$ deufmd. 2018205931

\title{
HLA Proteinlerinin GNM Metodu ile Dinamik Karakterizasyonu
}

\author{
Onur SERÇINOĞLU1 ${ }^{1}$ Pemra ÖZBEK*2, \\ ${ }^{1}$ Marmara Üniversitesi, Fen Bilimleri Enstitüsü, Biyomühendislik Anabilim Dalı, \\ 34722, İstanbul (ORCID: 0000-0003-1361-8160) \\ ${ }^{2}$ Marmara Üniversitesi, Mühendislik Fakültesi, Biyomühendislik Bölümü, 34722, \\ İstanbul (ORCID: 0000-0002-3043-0015)
}

(Alınış / Received: 03.03.2017, Kabul / Accepted: 01.02.2018,

Online Yayınlanma / Published Online: 15.05.2018)

Anahtar Kelimeler Protein dinamiği,

Gaussian ağ yapı modeli,

HLA,

Hızlı modlar
Özet: Biyolojik sistemler, birbirleri ile sürekli bilgi alışverişinde bulunan ağyapılar, biyolojik moleküller de bu yapının temel noktaları olarak tanımlanabilirler. Yaşamsal süreklilik açısından sistemin herhangi bir noktasında oluşacak bir sinyalin, hücreler arasında, hücre içinde veya hücre dışından hücre içine iletilmesi büyük önem taşımaktadır. Bu çalışmada, sistematik bir çerçevede HLA (İnsan Lökosit Antijenleri-Human Leukocyte Antigen) molekülleri üzerinde çalışılmıştır. HLAlar hücrelere yapışan yabancı proteinleri tanıyarak kendinden olan ve olmayanı ayırmakta kullanılır, bağışıklık sisteminin temelini oluştururlar. Çalışma kapsamında hesapsal bir yöntem olan Gaussian Ağ yapı modeli uygulanarak HLA sınıf 1 grubuna mensup yapıların yüksek frekanslarda öne çıkan bölgeleri tespit edilmiştir. Tüm moleküllerde hızlı modlarda aynı rezidülerin ön plana çıktı̆̆ı görülmekte olup bu rezidülerin arasında bir iletişim patikası olduğu düşünülmektedir.

\section{Dynamic Characterization of HLA Molecules by GNM}

\begin{tabular}{ll}
\hline Keywords & $\begin{array}{l}\text { Abstract: Biological systems communicate within a network and } \\
\text { Protein Dynamics, } \\
\text { baussian network }\end{array}$ \\
$\begin{array}{l}\text { model, } \\
\text { FLA, }\end{array}$ & $\begin{array}{l}\text { For the continuation of life, it is necessary for the signals to be } \\
\text { transmitted within and among the cells in a living organism. This }\end{array}$ \\
& study is conducted on HLA (Human Leukocyte Antigen) structures \\
in a systematic manner. HLAs having a role in immune system \\
recognize the foreign substances and attack them. By employing \\
Gaussian Network Model (GNM) on HLA class I molecules, the \\
residues that are energetically active at high frequency modes are \\
detected. In all the molecules, same residues are observed to have \\
the highest fluctuating profile, which are thought to form an \\
interaction network.
\end{tabular}

*Sorumlu yazar: pemra.ozbek@marmara.edu.tr 


\section{Giriş}

Proteinler/biyolojik makro moleküller hücreyi oluşturan yapı taşlarıdırlar. Esnek ve dinamik bir yapıya sahip olan proteinler, hücrenin yaşamsal fonksiyonlarını sağlamak için birbirleri ile iletișim kurarlar. Hücreye dişarıdan gelen veya hücre içerisinde olușan etkilerin ve/veya bu etkilere karşı oluşturulan tepkilerin hücre içinde bir yerden başka bir yere veya hücre zarına iletimi bu moleküller arasındaki etkileşimler sayesinde gerçekleşmektedir. Moleküller kendilerine ulaşan bir sinyale tepki olarak, yapısal birtakım değișikliklere gidebildiği gibi, bazen de yalnızca içsel dinamiğindeki değișikliklerle de kendilerinden sonraki adıma iletirler. Sinyal iletim mekanizmasındaki bozukluklar protein fonksiyonuna etki eden mutasyonlarla ilişkilendirilebilir.

Omurgallarda bulunan MHC (Major Histocompatibility Complex, Büyük Doku Uygunluk Kompleksi) sistemi insanlarda ilk kez lökositlerde gözlemlenmiş olmasından dolayı İnsan Lökosit Antijenleri-Human Leukocyte Antigen (HLA) olarak adlandırılmıştır. Genetik bilgisi 6 numaralı kromozomun kısa kolunda yerleșik bulunan HLA özellikleri doku özellikleridir. Bağıșıklık sistemi fonksiyonları ile iliş̧ili olup tıpkı kan grupları gibi kalıtsaldır. Bu genlerdeki proteinler antijen olarak da bilinirken bağışıklık sistemi açısından son derece önemlidir. HLAlar hastalıklara karşı savunma mekanizması ve kanserle mücadelede etkin role sahipken otoimmün sistemiyle de ilişkilidir. HLAlar tarafindan kodlanan proteinler kişiye özeldir ve bağışıklık sistemi tarafindan kendinden olan ve olmayanı ayırmakta kullanılır. Bu sayede hastalık tetikleyici yabancı proteinlere karşı savunma mekanizması oluşturur. Hücrelere yapışan yabancı proteinleri tanır, savunma hücreleri de onlara saldırır. Bazı durumlarda ise vücudun kendi hücrelerine de tıpkı yabancı hücrelere saldırdığı gibi saldırır ve otoümmin hastalıklarına sebep olur [1]. $\mathrm{Bu}$ hastalıkların mekanizması ya da sebebi halen daha çözülememiş konulardan olup araștırmaların çoğu otoümmin hastalıkların hangi genle ilişskili olduğunu tayin edip sonrasında da bu genlerin işleyiş̧ mekanizmasını anlayarak hastalıkların önüne geçmeye odaklanmıștır [2]. HLA proteinlerine dair bilgilerin birçoğu organ bağışı çalışmalarından sağlanmıştır [3]. IMGT/HLA veri bankasında [4] yaklaşı 9000 HLA dizisi bulunmasına rağmen belirli sayıda proteinin 3 boyutlu yapı bilgisi mevcuttur. Organ nakillerinde HLA özelliklerinin (doku özellikleri) uyumu son derece önemlidir, aksi takdirde bağışıklık sistemi tarafından diğer insanların doku antijenleri yabancı bir doku olarak algilanır ve reddetme tepkilerine yol açabilir. Fizyolojik işlevleri protein antijenlerinden kaynaklanan peptidleri antijene özgül T lenfositlerine göstermektir. MHC lokusu tüm hayvanlarda bulunan bir gen koleksiyonudur. Tüm türlerde MHC lokusu iki set olarak birçok polimorfik gen bulundurur, bunlar sinif I ve sinif II MHC genleri olarak anılır. Bu genler $\mathrm{T}$ hücrelerine peptid gösteren sinıf I ve sinıf II MHC moleküllerini kodlar.

HLA alfa-büklümlerle(helix) birbirine bağlı beta-sheetlerden oluşan alfa/beta motif oluşturan bir moleküldür (Şekil 1). $\beta 2$-mikroglobülin antiparalel beta-sheet döngülerle(loop) birbirine bağlıdır. Ayrıca beşik yapı modeli de göstermektedir. Her bir sınıf I molekülü bir $\alpha$ zinciri ve ona kovalan bağlı olmayan bağlarla bağlanan, $\quad \beta 2$ mikroglobülin olarak adlandırılan ve MHC dışında kodlanan bir proteinden oluşur. Sınıf I molekülünün amino ucunun $\alpha 1$ ve $\alpha 2$ büklümleri 8-11 amino asit uzunluğunda peptidlerin 
yerleşebileceği büyüklükte bir peptid bağlama oluğu oluşturur. Peptid bağlama oluğunun tabanı
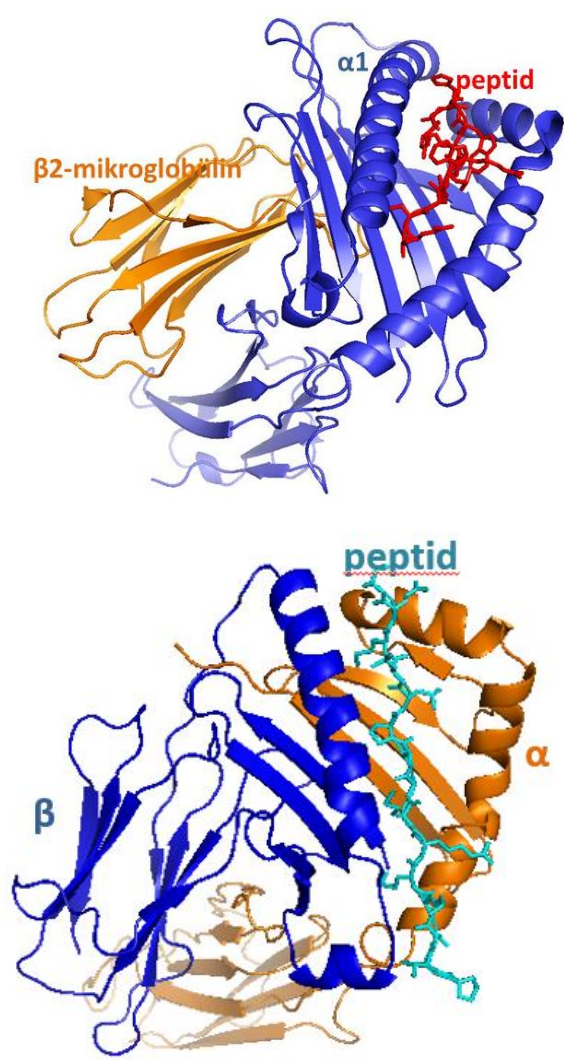

Şekil 1. Sinıf I HLA-B*27:09 aleli olan $10 \mathrm{~F} 2$ [5] protein yapısının (üst) ve Sinıf II HLA-DR3 yapisı olan 1A6A [6] proteininin (alt) Pymol ("The PyMol Molecular Graphics System, Version \#, Schrodinger, LLC.”) gösterimi

lenfositlerine gösterilecek peptidlerin bağlandığı kısım, oluğun yanları ve üst kısmı ise $\mathrm{T}$ hücre reseptörü ile temas halinde bulunan kısımdır. Sınıf I moleküllerinin polimorfik rezidüleri, yani farklı bireylerin MHC molekülleri arasında farklılık gösteren amino asitleri, $\alpha$ zincirinin $\alpha 1$ ve $\alpha 2$ alt birimlerinde yer alır. Zincirin $\alpha 3$ birimi değişken değildir ve T hücre eş-reseptörü CD8'in bağlanma noktasını içerir. Her sınıf II MHC molekülü bir $\alpha$ ve bir $\beta$ zincirinden olușur. Her iki zincirin amino ucu, $\alpha 1$ ve $\beta 1$ alt birimleri, polimorfik noktaları içerir ve 10-30 amino asit uzunluğunda peptidlerin yerleşebileceği büyüklükte bir peptid bağlama oluğu oluşturur. Değişken olmayan $\beta 2$ alt birimi T hücre eş-reseptörü CD4'ün bağlanma noktasını içerir.

$\mathrm{Bu}$ çalışma kapsamında üç boyutlu protein yapısı belli olan HLA proteinleri literatür aracılı̆̆ ile sinıflarına göre gruplanarak bir veri seti hazırlanmıştır. Hesapsal yöntem olarak Elastik A $\breve{g}$ modellerinden Gaussian Ağ Yapı modeli $[7,8]$ kullanılarak HLA sınıf I molekülleri genelinde belirgin bir patikanın varlı̆̆ araştırılmıştır.

\section{Materyal ve Metot}

\subsection{Veri Setinin Oluşturulması}

PDB [10] veritabanı arama fonksiyonu kullanılarak HLA araması sonucu toplam 475 yapı sonuç olarak listelenmektedir. 475 yapı içerisinde 66 yapının 3D yapısında ribozom kompleksi olduğu tespit edildiğinden bu 66 yapı elenmiştir. $\mathrm{Bu}$ bilgiye ek olarak PDB veritabanında HLA sinıfina göre bir gruplama yapılmadığından bu amaç için özel olarak oluşturulmuş olan IEDB [9] veritabanında arama fonksiyonu kullanılarak 3D MHC araması yapılmıștır. Arama sonucunda 322 yapı listelenmiştir. $\mathrm{Bu}$ iki liste birbirleriyle karşılaştırılıp birleştirilmiştir. Daha sonra insandan elde edilmemiş olan girdiler elenerek 386 adet yapı içeren son liste oluşturulmuştur. 386 yapıdaki dağılım şu şekildedir:

- 186 tanesi HLA-A

- 121 tanesi HLA-B

- 3 tanesi HLA-C

- 63 tanesi HLA-D

- 8 tanesi HLA-E

- 5 tanesi HLA-G'dir (Şekil 2). 


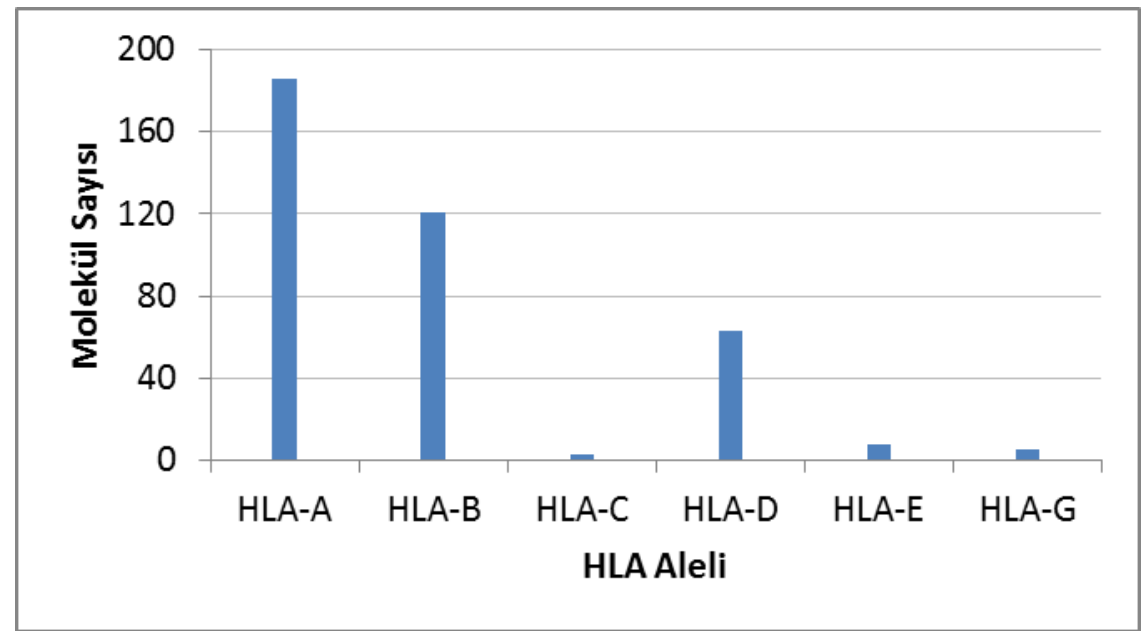

Şekil 1. Verisetinde yer alan HLA alel tiplerinde bulunan molekül sayısı

Her bir alel grubu içerisindeki sınıflandırılma Şekil 3'de verilmiştir. Buradaki yatay kolonlar, her bir alel grubundaki üç boyutlu yapısı belirli olan protein sayısını sembolize etmektedir.

Verisetindeki tüm moleküller X-Ray deney metoduyla elde edilmiştir. PDB [10] ve IEDB [11] veritabanlarından gelen bilgilerde eksik olan peptid sekans bilgisi ve molekül zincir bilgisi PDBsum [12] ve literatür aracılığı ile tamamlanmıștır. IEDB veritabanından gelen alel tipleri verisinde eksik olan kısımlar ve PDB verilerinde karşılaşılabilen eksik/fazla rezidülerin belirlenmesi için ccPDB [13] sunucusu kullanılarak sınıf I moleküllerin HLA zincirleri toplu halde FASTA formatında elde edilmiş, daha sonra FASTA dosya formatında çıktı alınarak filogenetik ağaç şeması oluşturulması için "Phylogeny.fr Robust Phylogenetic Analysis For The Non-Specialist" [14] sunucusunda giriș dosyası olarak kullanılmış ve her bir alel için filogenetik ağaç şemaları elde edilmiştir. Böylelikle farklı moleküllerin HLA zincirleri arasındaki farklılıklar ve benzerlikleri elde edilmiștir. Aynı bölgede gruplanan moleküller genellikle aynı alel tipine ait olmakla birlikte, tek moleküllerin olușturduğu ayrı gruplar genellikle PDB verisinde bulunan hataları ve eksiklikleri belirtmektedir (örn. deneysel olarak belirlenemeyen ancak varlığı bilinen rezidüler).

Tüm protein yapıları için alel tipi, peptid tipi, çözünürlük, varsa PDB verisindeki mutasyon ve eksik rezidüler bilgileriyle birlikte 386 yapı içeren veriseti tamamlanmıștır. Çalıșmada kullanılan veri seti detaylı olarak Ek Tablo 1'de yer almaktadır. $\mathrm{Bu}$ çalışma kapsamında burada yer alan sınıf 1 molekülleri üzerinde detaylı olarak çalıșılmıștır. 
SINIF 1

\begin{tabular}{|c|c|c|c|}
\hline$A^{*} 68: 01$ & 13 & $B * 57: 03$ & 16 \\
\hline$A * 24: 02$ & 17 & $B * 57: 01$ & 16 \\
\hline$A * 11: 01$ & 14 & $B * 53: 01$ & 2 \\
\hline$A^{*} 03: 01$ & 13 & $B * 52: 01$ & 1 \\
\hline$A^{*} 02: 07$ & 1 & $B * 51: 01$ & 2 \\
\hline & & $B * 44: 05$ & 17 \\
\hline A“UL:Ub & 1 & $B * 44: 03$ & 15 \\
\hline$A^{*} 02: 03$ & 1 & $B * 44: 02$ & 9 \\
\hline$A^{*} 02: 01$ & 164 & $B^{*} 41: 04$ & 1 \\
\hline$A^{*} 01: 01$ & 2 & $B^{*} 41: 03$ & 1 \\
\hline & & $B \star 35: 08$ & - 16 \\
\hline$C^{*} 04: 01$ & 2 & $B * 35: 01$ & 21 \\
\hline$C * 03: 04$ & 1 & $B \star 27: 09$ & 10 \\
\hline$E^{*} 01: 03$ & 2 & $B * 27: 05$ & - 17 \\
\hline & & $B^{*} 15: 01$ & 13 \\
\hline E.T.U1 & 16 & $B^{\star} 14: 02$ & 1 \\
\hline & & $B^{*} 08: 01$ & 12 \\
\hline G*01:01 & 6 & $B * 07: 02$ & 1 \\
\hline
\end{tabular}

Şekil 2. Verisetinde yer alan HLA alellerinin kendi içinde sınıflandırılması
SINIF 2

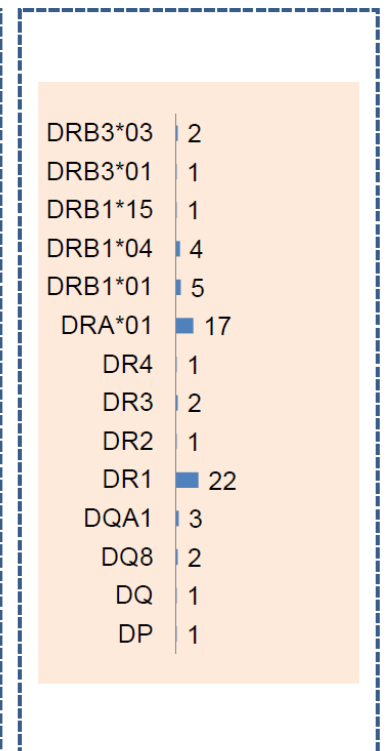

\subsection{Gaussian Ăg Yapı Modeli'nin Tüm Sınıf I Moleküllerine Toplu Olarak Uygulanması}

Gaussian A $\breve{g}$ yapı modeli (GNM) [7, 8] veri setindeki tüm sınıf 1 moleküllerine toplu olarak uygulanmıştır. Bu metot ile tek tek her bir protein yapisının harmonik titreșimsel analizi ile yüksek frekanslı modlardaki hareketleri elde edilmiştir. GNM çıktısı olarak da her bir rezidünün diğer rezidüler ile yapmış olduğu dalgalanmalarının toplamını ifade eden $\mathrm{D}$ değeri gösterilmiștir. $\mathrm{Bu}$ sayede proteinlerin yüksek frekanslarda ortak ve farklılık gösteren bölgeleri tespit edilmiş olup, fonksiyonlarındaki farklılıklar dalgalanmalarındaki farklılıklar ile açıklanmaya çalışılmış, mutasyonların dalgalanmalara etkisi araștırılmıştır. Bu ve benzeri enerji bazlı hesapsal yaklaşımlar geliştirilerek iletişim patikası üzerinde yer alan rezidülerin tahmini yapılmaktadır $[15$, 16]. Bu çalışmada da aynı gruba mensup proteinlerde benzer iletişim mekanizmalarının varlığı incelenmiştir.
İncelenen her bir protein yapısı için, PDB dosyasında yer alan her amino asitin sadece alfa karbonlarının koordinat değerleri esas alınmış ve Kirchhoff matrisi $\left(\Gamma_{i j}\right)$, aşağıdaki gibi oluşturulmuştur:

$\Gamma_{i j}=\left\{\begin{array}{l}-1 \quad \text { ĕger } i \neq j \text { ve } R_{i j} \leq r_{c} \\ 0 \quad \text { ĕger } i \neq j \text { ve } R_{i j}>r_{c} \\ -\sum_{i, j \neq i} \Gamma_{i j} \text { ĕger } i=j\end{array}\right.$

Kirchhoff matrisi, her bir amino asitin birbiri ile belirlenmiş olan bir sınır etkileşim mesafesi $\left(r_{c}\right)$ dahilinde bağlı olup olmadığı bilgisini içeren ve böylelikle protein yapısının topolojik bilgisini kabaca içeren bir matristir. $\mathrm{Bu}$ çalışmada sınır etkileșim mesafesi olarak, literatürde de sıklıkla kullanılan $7 \AA ̊$ A kullanılmıștır. 
Gaussian A $\breve{g}$ Yapı Modeli'nde i ve j rezidüleri arasındaki çapraz korelasyon $\left\langle\Delta R_{i} \cdot \Delta R_{j}\right\rangle$, Kirchhoff matrisinin tersi ( $\left[\Gamma^{-1}\right]_{i j}$ ) ile aşağıdaki gibi ilintilidir [8].

$$
\left\langle\Delta R_{i} \cdot \Delta R_{j}\right\rangle=\frac{3 k_{B} T}{\gamma}\left[\Gamma^{-1}\right]_{i j}
$$

Yukarıdaki eşitlikte $k_{B} \quad$ Boltzmann katsayısını (J/K), $T$ mutlak sıcaklık değerini (K) ve $\gamma$ da ağ yapı modelinde yay sabitini ifade etmektedir. Bu değerlerin hepsi birer sabit sayı olduğundan, $\left\langle\Delta R_{i} \cdot \Delta R_{j}\right\rangle$ ve $\Gamma_{i j}$ matrisleri birbirileri ile doğrudan ilişkilidirler. Bunun sonucunda da, sistemin tüm dinamiğini $\left[\Gamma^{-1}\right]_{i j}$ matrisi belirlemektedir. Bu çalışmada hesaplanan çapraz korelasyon matrisleri, bu ilintiler doğrultusunda doğrudan $\left[\Gamma^{-1}\right]_{i j}$ matrisine eşit olarak kabul edilmişlerdir. Dolayısıyla fiziksel herhangi bir birim ile ifade edilmemişlerdir.

\section{$\left[\Gamma^{-1}\right]_{i j}$ matrisi, doğrudan Kirchhoff} matrisi'ne tekil değer ayrışımı uygulanarak bulunur:

$$
\begin{aligned}
& \left\langle\Delta R_{i} \cdot \Delta R_{j}\right\rangle \cong\left[\Gamma^{-1}\right]_{i j} \\
& \cong\left[U \boldsymbol{\Lambda}^{-1} U^{T}\right]_{i j}
\end{aligned}
$$

Yukarıdaki eşitlikte $U$ özvektör matrisini, $\Lambda$ ise köşegen değerleri özdeğerlerden oluşan matrisi ifade etmektedir. $\Lambda$ matrisi aynı zamanda karakteristik kök matrisi olarak da isimlendirilir ve sistemin toplam hareketini temsil eden modların frekansını temsil eder. Tekil değer ayrışımı, aynı zamanda tekil olarak modları ifade eden özvektörlerin ve özdeğerlerin toplamı olarak da ifade edilebilir:

$$
\begin{aligned}
& \left\langle\Delta R_{i} \cdot \Delta R_{j}\right\rangle \cong\left[U \Lambda^{-1} U^{T}\right]_{i j} \\
& \cong \sum_{k}\left[\lambda_{k}^{-1} u_{k} u_{k}^{T}\right]_{i j}
\end{aligned}
$$

Yukarıdaki eşitlikte $\lambda_{k}$ k'ıncı modun özdeğerini, $\quad u_{k}$ ise k'ıncl modun özvektörünü ifade etmektedir. Tekil değer ayrışımını takiben yapılan bu işlem, sistemin eșitlik pozisyonundan yaptığ $\breve{1}_{1}$ dalgalanma hareketinin (titreşimlerinin), frekanslarına göre farklı modlara ayrılarak incelenmesine olanak sağlar. $\mathrm{N}$ amino asite sahip bir sistemin karakteristik kök matrisinin $(\Lambda)$ sifirdan farklı $\mathrm{N}-1$ adet modu bulunur.

$\lambda_{k}$ değerleri arasında düşük değere sahip olanlar en yavaş olan kolektif ve global hareketleri, yüksek değerler de en hızlı olan, sınırlı sayıda rezidünün katıldığı yerel hareketleri ifade ederler. $\mathrm{Bu}$ çalıșmada HLA moleküllerinde moleküler yapıda rezidüler arasındaki olası etkileşim patikalarının molekül topolojisinden bulunması amaçlandığından, frekansı yüksek olan yerel hareketlere odaklanılmıştır. Bu kapsamda en yüksek frekansa sahip olan ilk üç mod hesap kapsamına alınmıştır. Her üç mod için ayrı olarak $i$ ve $j$ rezidüleri arasındaki göreli dalgalanmayı veren ortalama kareler dalgalanma matrisleri $\left\langle\Delta R_{i j}{ }^{2}\right\rangle$, aşağıdaki gibi hesaplanmıștır:

$$
\begin{aligned}
& <\Delta R_{i j}{ }^{2}>=<\left(\Delta R_{i}-\Delta R_{j}\right)^{2}> \\
& =<\Delta R_{i}^{2}>+<\Delta R_{j}^{2}>-2<\Delta R_{i} \Delta R_{j}>
\end{aligned}
$$


Ek olarak, her üç modu da temsil eden ve özdeğerlere göre hesaplanmış bir "ağırlıklı ortalama" kareler dalgalanma matrisi de aşağıdaki gibi hesaplanmıştır:

$$
<\Delta R_{i j}{ }^{2}>_{1-2-3}=\frac{\sum_{k=1}^{3}<\Delta R_{i j}{ }^{2}>_{k} \cdot \lambda_{k}^{-1}}{\sum_{k=1}^{3} \lambda_{k}^{-1}}
$$

Ortalama kareler dalgalanma matrisi, her bir $i$ rezidüsünün, her bir $j$ rezidüsü ile olan göreli dalgalanmaları arasındaki korelasyonu ifade etmektedir. A $\breve{g}$ yapısında önemli rol oynayan rezidüleri bulabilmek için, simetrik olan $\left\langle\Delta R_{i j}{ }^{2}\right\rangle$ matrisinde her bir i rezidüsü için $\mathrm{i}$ satırında veya kolonunda bulunan değerler toplanarak, gösterge bir değer elde edilebilir:

$$
D_{i}=\sum_{j}<\Delta R_{i j}{ }^{2}>
$$

Yukarıdaki eşitlikte $D_{i}$ değeri, $i$ rezidüsünün ağ yapısı içerisinde diğer tüm rezidüler ile olan dalgalanmalar aracılığı ile etkileşiminin toplamını ifade eder. Yüksek $D_{i}$ değerine sahip olan rezidülerin, ilgili moddaki harekette "merkezi" bir rol oynadıkları varsayılabilir. Rezidüler arasındaki ortalama kareler dalgalanma matrisinin, sistemin dışarıdan aldığı enerji sonucu oluşan ortalama enerji dalgalanmaları $(\Delta U)$ ile de ilintili olduğu varsayılabilir.

$$
\left\langle\Delta U \cdot\left(\Delta R_{i j}\right)^{2}\right\rangle=k \cdot T \cdot\left\langle\left(\Delta R_{i j}\right)^{2}\right\rangle
$$

Dolayısı ile $D_{i}$ değeri aynı zamanda enerji dalgalanmaları ile de aşağıdaki gibi ilişkilidir:

$$
\begin{aligned}
& D_{i}=\sum_{j}<\Delta R_{i j}{ }^{2}> \\
& =\frac{1}{k \cdot T} \sum_{j}\left\langle\Delta U \cdot\left(\Delta R_{i j}\right)^{2}\right\rangle
\end{aligned}
$$

Yukarıda detayları verilen GNM metodu, veri setindeki tüm sınıf I moleküllerine toplu olarak uygulanmıştır. Sınıf I moleküllerinde özellikle ilgi konusu olan bölge peptid bağlanma bölgesi olduğundan, metod sadece antijen zinciri (HLA zinciri) temel alınarak uygulanmıştır. $\mathrm{Bu}$ zincir, peptidin bağlandığı $\alpha 1, \alpha 2$ ve ayrıca $\alpha 3$ alt birimlerinden oluşur ve kristalografide belirlenebilen toplam amino asit sayısı bir kaç istisna dışında 276'dır.

\subsection{HLA Yapısında Rezidü Korunurluğu Değerlerinin Elde Edilmesi}

HLA yapısında bulunan her bir aminoasit rezidü pozisyonunun farklı HLA dizileri de göz önünde bulundurularak korunurluğunu elde etmek için, ConSurf 2016 sunucusu kullanılmıştır [17]. Sunucu, verilen bir PDB yapısı ile başlayarak, homolog dizileri otomatik olarak UniRef90 veri tabanından bulmakta, bunların çoklu dizi eşleşmelerini gerçekleştirerek diziler arası evrimsel ilişkiyi ifade eden filogenetik ağaç oluşturmaktadır. Bu veri, dizideki her bir pozisyonun evrimsel değişim hızını tahmin etmek amacıyla kullanılmaktadır.

Veri setinde bulunan her bir Sinıf I HLA aleli için, yapı çözünürlük değeri (Angstrom cinsinden) en düşük olan yapılar seçilmiştir. Bu seçilen yapıların her biri için ConSurf sunucusu kullanılarak rezidü pozisyonlarının korunurluğunu ifade eden ve 0 ile 9 arasında değișen "skor" değerleri elde edilmiştir. HLA yapısındaki her bir pozisyon için tek bir skor değeri elde etmek için, veri setindeki her bir yapıda, ilgili pozisyonun skor değerinin aritmetik ortalaması alınmıştır. 


\subsection{Ortalama Kare-Kök Sapma Hesaplaması}

Olușturulan veri setinde bulunan HLA yapıları arasındaki Ortalama Kare-Kök Sapma (RMSD) hesabı, veri setinde bulunan her bir Sınıf I HLA yapısının bir diğerine üstüne çakıştırılarak, yapılarak arasında alfa karbonların aralarındaki ortalama mesafelerinin ortalaması hesaplanarak gerçekleştirilmiştir. Buna göre, iki yapı arasındaki RMSD değeri ne kadar yüksek ise, aralarındaki benzerlik o kadar düşüktür. Dolayısıyla, RMSD, iki yapı arasındaki benzerliğin/ bir göstergesi olarak işlev görür.

\section{Bulgular}

Molekül sayısı oldukça fazla olduğundan, sonuçlar belirtilen modların ve ağırlıklı ortalama modunun değerlerinin topluca gösterimi olarak Şekil 4 ve Şekil 5'de A1 ve B1 bölmelerinde verilmiștir. Her moddan elde edilen baskın (göreli yüksek) D değerlerinin molekül üzerinde hangi rezidülere karşılık geldiği de sırasıyla A2 ve B2 bölmelerinde gösterilmiștir. Buna göre Şekil 4'de A1 ve A2 en hızlı mod olan mod 1'e, B1 ve B2 en hizlı ikinci mod olan mod 2'ye, Şekil 5'de ise A1 ve A2 en hızlı üçüncü mod olan mod 3'e, B1 ve B2 ise bu modların ağırlıklı ortalama modu olan mod 1-2-3'e denk gelmektedir. A1 ve B1 bölmelerinde verilen grafiklerde $\mathrm{X}$ ekseni antijen zincirinin sıralı rezidü sayısını ifade ederken, Y ekseni ise genlere göre gruplandırılmış molekülleri ifade etmektedir. Y ekseninde gen seviyesinde gruplandırmanın ötesinde herhangi bir gruplandirma yoktur ve molekülün herhangi bir șekilde artan veya azalan kantitatif bir özelliğini ifade etmemektedir. A2 ve B2 bölmelerinde baskın $\mathrm{D}$ değerine sahip olan rezidüler van der Waals kürecikleri şeklinde gösterilmișlerdir.

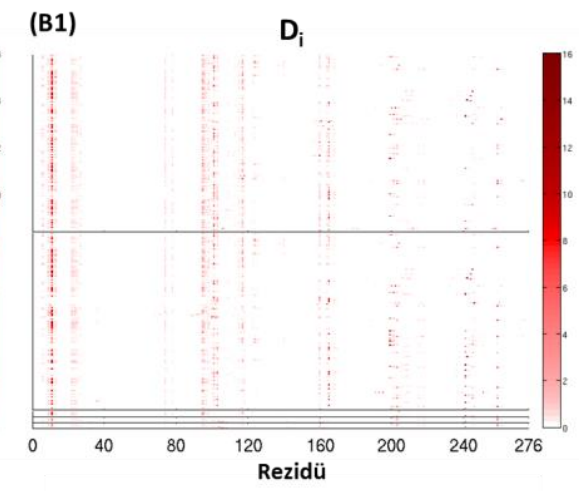

(B2)

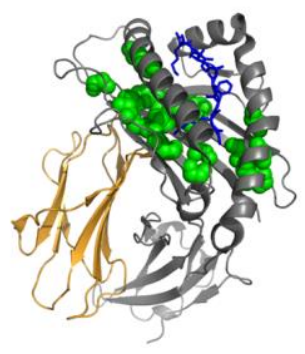

Şekil 4. Sınıf I için (A1\&A2)GNM mod 1 Di değerleri ve üç boyutlu yapı üzerinde etkileşim patikalarının gösterimi (kırmızı küreler) (B1\&B2) GNM mod 2 ve Di değerleri üç boyutlu yapı üzerinde etkileşim patikalarının gösterimi (yeşil küreler) 


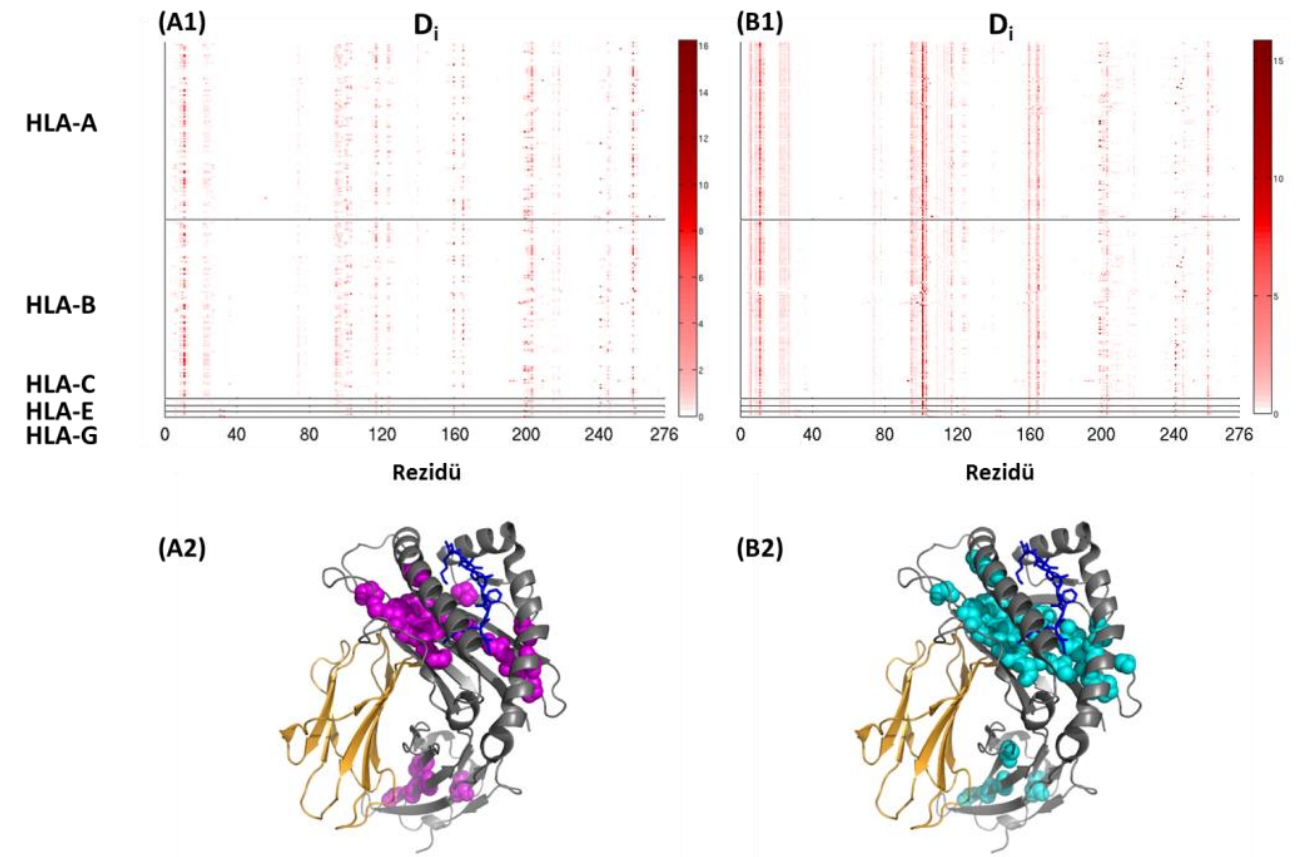

Şekil 5. Sınıf I için (A1\&A2)GNM mod 3 Di değerleri ve üç boyutlu yapı üzerinde etkileşim patikalarının gösterimi (pembe küreler) (B1\&B2) GNM mod 1-2-3 Di değerleri ve üç boyutlu yapı üzerinde etkileşim patikalarının gösterimi (mavi küreler)

Şekil 4 A1 bölmesinde de görülebileceği üzere, en hizlı mod olan mod 1'de Sinıf I moleküllerinin tamamının büyük oranda aynı rezidüler etrafında bir iletişim patikasına sahip olduğu gözlenmektedir. Özellikle Cys-101 numaralı rezidü, iletișim patikasında merkezi bir rol oynamakta, patikada bunun dişında Arg-6, Tyr-27 ve Leu-160 numaralı rezidüler öne çıkmaktadır. $\mathrm{Bu}$ rezidülerin HLA molekülünün alfa-1 bölgesinin Arg-6 numaralı rezidüsünden alfa-2 bölgesinin Leu-160 numaralı rezidüsüne uzanan bir yapıda birbirleri ile etkileşim halinde olduğu gözlenmiştir.

En hızlı ikinci mod olan mod 2, benzer bir rezidü etkileşim profili vermektedir (Șekil 4 B1 bölmesi). Mod 1 ile arasındaki farklılık, Ser-13 numaralı rezidünün tüm Sinıf I moleküllerinde daha merkezi bir rol oynamasıdır.
En hızlı üçüncü mod olan mod 3, yine aynı profilde, mod 2'ye benzer sonuç vermektedir (Şekil 5 A1 bölmesi). Diğer modlar ile arasındaki fark, bu modda $\alpha 3$ alt biriminde yer alan Thr-200 ve Thr240 numaralı rezidüler etrafında kümelenen baskın rezidülerin bu modda daha belirgin olarak gözlenmesidir.

Şekil 4 ve Şekil 5'te bahsedilen profilden sapmalar da gözlenmektedir. GNM yönteminde, bu şekilde yapısal olarak farklı bölgeler içerisinde görülen yerel titreșimlerin farklı moleküler yapılarında frekanslar arasında kaymalar yapabildiği bilinmektedir. 


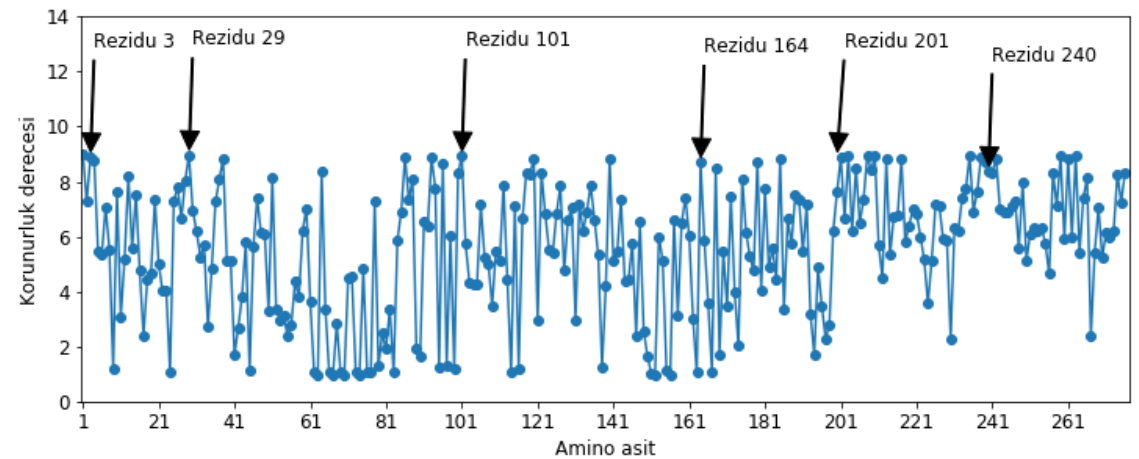

Şekil 6. Sınıf I HLA yapılarında her bir amino asit pozisyonunun ConSurf 2016 sunucusundan elde edilen korunurluk dereceleri.

Dolayısıyla, bu sapmaların belirgin olarak farklı iletişim patikalarını ifade etmedikleri, bu sebeple de farklı aleller arasindaki mutasyonlardan kaynaklanan farklı profilleri ifade etmedikleri değerlendirilmiştir. Bu tez, mod 1,2 ve 3 'ten daha önce açıklandığı şekliyle elde edilen ağırlıklı ortalama modu olan mod 1-2-3'ün Şekil 5 B1 bölmesinde verilen $D_{i}$ profili tarafından da doğrulanmaktadır. Bu grafikte de görülebileceği üzere, özellikle baskın olarak görülen rezidüler, en hızlı üç modda tüm alel tiplerinde ortak olarak gözlenmektedir. Veri setindeki tüm HLA sınıf I yapıları arasındaki ortalama karekök sapma (RMSD) dağılımının 0.5 - $1 \AA$ aralığında olması (Ek B), farklı aleller arasında katlanmış HLA yapısının belirgin şekilde farklılık göstermediğini göstermektedir. Ancak, RMSD dağılımının $0.7 \AA ̊$ etrafında kümelenmiş olması, yapılar arasında gözle görülemeyen farklılıkları da ifade edebilir. $\mathrm{Bu}$ olası farklılıkların, HLA protein dinamiğinde hızlı modlarda rol oynayan amino asitlerin pozisyonlarında değissikliğe yol açmadığı gözlemlenmiştir. Ancak, kullandığımız GNM yöntemin iri taneli bir hesapsal yöntem olduğu ve amino asit yan zincirleri arasındaki farklılığ doğrudan hesaba katmadı̆̆ da göz önünde bulundurulmalıdır.
Elde edilen bu rezidüler ve oluşturdukları iletişim patikasının HLA molekülünün fonksiyonundaki rolü literatürde net olarak ortaya konulmamıştır. 1-180 arası rezidülerin tamamı peptit bağlanmasında olası rol sahibi olabilir. Ancak, hızlı hareket modlarının proteinin katlanmış halini korumada önemli rol oynadığı ve dolayısıyla proteinin ne kadar kararlı olacağını belirleyen önemli faktörlerden olduğu raporlanmıștır $[8,16]$. HLAA02:01 alelinde Cys-101 ve Cys-164 arasında bir disülfit köprüsünün oluştuğu ve bu köprü mutasyon ile bozulduğunda protein kararlılığının etkilendiği [18]. Cys-164 ve bu rezidüye dizi komşuluğu bulunan rezidüler Cys101 ile birlikte GNM hizlı modlarında önemli rol oynamaktadırlar.

HLAların insandaki en polimorfik protein olduğu dikkate alındığında, elde edilen iletişim patikasındaki rezidülerle bu rezidülerin korunurluk derecelerinin karşılaştırılması, doğal olarak oluşan HLA polimorfizminin protein işlevi açısından açıklanmasında faydalı olabilir. HLA yapısındaki her bir rezidü pozisyonunun korunurluk değerleri ConSurf sunucusu ile elde edilmiștir. Şekil 6, ConSurf sunucusundan elde edilen korunurluk değerlerini göstermektedir. Korunurluk değerleri göreli yüksek olan GNM hızlı 
modlarındaki iletişim patikasında yer alan veya dizi komşusu olan rezidüler, oklar ile belirtilmiștir. Buna göre, GNM hızlı modlarında rol oynayan rezidülerin belirgin bir şekilde dizideki diğer rezidülere göre daha korunmuş amino asitler oldukları gözlenmektedir.

\section{Sonuç}

HLA sınıf 1 molekülleri üzerine uygulanan GNM yöntemi sonucunda hızlı modlarda istisnasız aynı rezidülerin ön plana çıktığ görülmektedir. $\mathrm{Bu}$ rezidülerin (Arg-6, Tyr-27, Cys-101, Glu-163, Val-165) arasında bir iletişim patikası olduğu düşünülmektedir. Mod sayısının artması ile mevcut bu rezidülere ek olarak özellikle Ser-13, Gly-120, Thr-200 ve Thr-240 numaralı rezidülerin de profillerde baskın olarak görüldüğü gözlemlenmiştir. Aynı sisteme mensup 10 protein üzerinde yapılan önceki çalışmalarda da [15] aynı bölgelerin öne çıktığı bulunmuștu. Bu çalışma ile bu bölgelerin HLA sınıf 1 sistemi üzerinde genelleștirilmesi mümkün olabilmiştir. Bunun yanı sıra, elde edilen rezidülerin HLA yapısında göreli olarak daha korunmuş amino asitler olduğu gözlemlenmiştir. $\mathrm{Bu}$ bulgu, protein dinamiğinde hızlı titreşim gösteren amino asitlerin protein kararlılığında önemli rol oynadığı değerlendirdiğinde, HLA proteininde görülen polimorfizm ile protein kararlılığı arasında var olduğu bilinen ilişkiyi hesapsal olarak da göstermektedir. Daha sonraki çalışmalarda bu iletişim patikasının farklı yöntemler ile de tayin ve tespitinin yanısıra mutasyonların bu bölgelere etkileri üzerinde çalışılması mümkündür.

\section{Teșekkür}

Bu çalışma TÜBİTAK 113M293 nolu projenin sağladığı destek ile tamamlanmış olup, TÜBİTAK'a desteğinden dolayı teşekkür ederiz.

\section{Kaynakça}

[1] Gough, S.C. ve M.J. Simmonds. 2007. The HLA Region and Autoimmune Disease: Associations and Mechanisms of Action. Curr Genomics , Cilt 8(7), s. 453-65.

[2] Ghodke, Y. vd. 2005. HLA and disease. Eur J Epidemiol. Cilt 20(6), s. 475-88.

[3] Schreuder, G.M. vd. 2001. The HLA Dictionary 2001: a summary of HLA-A, -B, -C, -DRB1/3/4/5 and DQB1 alleles and their association with serologically defined HLA-A, $B,-C$, -DR and -DQ antigens. Eur J Immunogenet, Cilt 28(6), s. 565-96.

[4] Robinson, J. vd. 2011. The IMGT/HLA database. Nucleic Acids Res, 2011. Cilt 39(Database issue), s. D1171-6.

[5] Starikov, E.B., L. Nilsson ve M. Hulsmeyer. 2004. A single residue exchange between two HLA-B27 alleles triggers increased peptide flexibility. Eur Biophys J, Cilt 33(7), s. 651-5.

[6] Ghosh, P., vd. 1995. The structure of an intermediate in class II MHC maturation: CLIP bound to HLADR3. Nature, Cilt 378(6556), s. 457-62.

[7] Haliloglu, T., I. Bahar ve B. Erman. 1997. Gaussian dynamics of folded proteins. Phys Rev Lett, Cilt 79(16), s. 3090-3093.

[8] Bahar, I. vd. 1998. Vibrational dynamics of folded proteins: Significance of slow and fast motions in relation to function and stability. Phys Rev Lett. Cilt 80(12), s. 2733-2736.

[9] Ponomarenko, J. vd. 2011. IEDB3D: structural data within the immune epitope database. Nucleic Acids Res, Cilt 39(Database issue), s. D1164-70.

[10] Berman, H.M. vd. 2000. The Protein Data Bank. Nucleic Acids Res, Cilt 28(1), s. 235-42. 
[11] Vita, R. vd. 2015. The immune epitope database (IEDB) 3.0. Nucleic Acids Res, Cilt 43(Database issue), s. D405-12.

[12] de Beer, T.A. vd. 2014. PDBsum additions. Nucleic Acids Res. Cilt 42(Database issue), s. D292-6.

[13] Singh, H. vd. 2012. ccPDB: compilation and creation of data sets from Protein Data Bank. Nucleic Acids Res. Cilt 40(Database issue), s. D486-9.

[14] Dereeper, A. vd. 2008. Phylogeny.fr: robust phylogenetic analysis for the non-specialist. Nucleic Acids Res, 2008. Cilt 36(Web Server issue), s. W465-9.

[15] Haliloglu, T., A. Gul ve B. Erman. 2010. Predicting Important Residues and Interaction Pathways in Proteins Using Gaussian Network Model: Binding and Stability of HLA Proteins. Plos Computational Biology, Cilt 6(7).

[16] Ozbek, P., S. Soner ve T. Haliloglu. 2013. Hot Spots in a Network of Functional Sites. PLoS One, Cilt $8(9)$.

[17] Ashkenazy. H. vd., 2016. ConSurf 2016: an improved methodology to estimate and visualize evolutionary conservation in macromolecules. Nucleic Acids Research, Cilt 44(Web Server issue), s. W344W350

[18] Warburton RJ. vd., 1994. Mutation of the alpha 2 domain disulfide bridge of the class I molecule HLA$A^{*} 0201$. Effect on maturation and peptide presentation. Hum Immunol, Cilt 39(4), s261-71.

\section{Ekler}

Ek A. Çalışmada Kullanılan Veri Seti

Ek B. Veri Setinde Bulunan Sınıf I Yapıları Arasındaki Alfa-Karbon RMSD Dağılımı 
O. Serçinoğlu ve P. Özbek / HLA Proteinlerinin GNM Metodu ile Dinamik Karakterizasyonu

EK A - Çalışmada Kullanılan Veri Seti

Ek Tablo 1. Calıșmada Kullanılan Veri Seti

\begin{tabular}{|c|c|c|c|c|}
\hline PDB Adı & Sinıf & Alel Adı & Peptid & $\begin{array}{l}\text { Çözünürlük } \\
\text { (Å) }\end{array}$ \\
\hline $1 \mathrm{~W} 72$ & 1 & HLA-A*01:01 & EADPTGHSY & 2.15 \\
\hline 3B08 & 1 & HLA-A*01:01 & EADPTGHSY & 1.80 \\
\hline $1 \mathrm{AKJ}$ & 1 & HLA-A*02:01 & ILKEPVHGV & 2.65 \\
\hline $1 \mathrm{AO} 7$ & 1 & HLA-A*02:01 & LLFGYPVYV & 2.60 \\
\hline $1 \mathrm{~B} 0 \mathrm{G}$ & 1 & HLA-A*02:01 & ALWGFFPVL & 2.50 \\
\hline $1 \mathrm{~B} 0 \mathrm{R}$ & 1 & HLA-A*02:01 & GILGFVFTL & 2.90 \\
\hline 1BD2 & 1 & HLA-A*02:01 & LLFGYPVYV & 2.5 \\
\hline 1DUY & 1 & HLA-A*02:01 & LFGYPVYV & 2.15 \\
\hline 1DUZ & 1 & HLA-A*02:01 & LLFGYPVYV & 1.80 \\
\hline $1 \mathrm{EEY}$ & 1 & HLA-A*02:01 & ILSALVGIV & 2.25 \\
\hline 1EEZ & 1 & HLA-A*02:01 & ILSALVGIL & 2.30 \\
\hline $1 \mathrm{HHG}$ & 1 & HLA-A*02:01 & TLTSCNTSV & 2.60 \\
\hline $1 \mathrm{HHH}$ & 1 & HLA-A*02:01 & FLPSDFFPSV & 3.00 \\
\hline $1 \mathrm{HHI}$ & 1 & HLA-A*02:01 & GILGFVFTL & 2.50 \\
\hline $1 \mathrm{HHJ}$ & 1 & HLA-A*02:01 & ILKEPVHGV & 2.50 \\
\hline $1 \mathrm{HHK}$ & 1 & HLA-A*02:01 & LLFGYPVYV & 2.50 \\
\hline 1HLA & 1 & HLA-A*02:01 & 0 & 3.50 \\
\hline $1 \mathrm{I} 1 \mathrm{~F}$ & 1 & HLA-A*02:01 & FLKEPVHGV & 2.80 \\
\hline $1 \mathrm{IIY}$ & 1 & HLA-A*02:01 & YLKEPVHGV & 2.20 \\
\hline $1 \mathrm{I} 4 \mathrm{~F}$ & 1 & HLA-A*02:01 & GVYDGREHTV & 1.40 \\
\hline $1 \mathrm{I7R}$ & 1 & HLA-A*02:01 & FAPGFFPYL & 2.20 \\
\hline $1 \mathrm{I} 7 \mathrm{~T}$ & 1 & HLA-A*02:01 & ALWGVFPVL & 2.80 \\
\hline $1 \mathrm{I} 7 \mathrm{U}$ & 1 & HLA-A*02:01 & ALWGFVPVL & 1.80 \\
\hline 1IM3 & 1 & HLA-A*02:01 & LLFGYPVYV & 2.20 \\
\hline 1JF1 & 1 & HLA-A*02:01 & ELAGIGILTV & 1.85 \\
\hline 1JHT & 1 & HLA-A*02:01 & ALGIGILTV & 2.15 \\
\hline $1 \mathrm{LP9}$ & 1 & HLA-A*02:01 & ALWGFFPVL & 2.00 \\
\hline $10 G A$ & 1 & HLA-A*02:01 & GILGFVFTL & 1.40 \\
\hline 1P7Q & 1 & HLA-A*02:01 & ILKEPVHGV & 3.40 \\
\hline 1QEW & 1 & HLA-A*02:01 & FLWGPRALV & 2.20 \\
\hline 1QR1 & 1 & HLA-A*02:01 & IISAVVGIL & 2.40 \\
\hline $1 \mathrm{QRN}$ & 1 & HLA-A*02:01 & LLFGYAVYV & 2.80 \\
\hline 1QSE & 1 & HLA-A*02:01 & LLFGYPRYV & 2.80 \\
\hline $1 \mathrm{QSF}$ & 1 & HLA-A*02:01 & LLFGYPVAV & 2.80 \\
\hline 1S8D & 1 & HLA-A*02:01 & SLANTVATL & 2.20 \\
\hline $1 \mathrm{~S} 9 \mathrm{~W}$ & 1 & HLA-A*02:01 & SLLMWITQC & 2.20 \\
\hline
\end{tabular}


O. Serçinoğlu ve P. Özbek / HLA Proteinlerinin GNM Metodu ile Dinamik Karakterizasyonu

\begin{tabular}{|c|c|c|c|}
\hline 1S9X & 1 & HLA-A*02:01 & SLLMWITQA \\
\hline 1S9Y & 1 & HLA-A*02:01 & SLLMWITQS \\
\hline $1 \mathrm{~T} 1 \mathrm{~W}$ & 1 & HLA-A*02:01 & SLFNTIAVL \\
\hline $1 \mathrm{~T} 1 \mathrm{X}$ & 1 & HLA-A*02:01 & SLYLTVATL \\
\hline $1 \mathrm{~T} 1 \mathrm{Y}$ & 1 & HLA-A*02:01 & SLYNVVATL \\
\hline $1 \mathrm{~T} 1 \mathrm{Z}$ & 1 & HLA-A*02:01 & ALYNTAAAL \\
\hline $1 \mathrm{~T} 20$ & 1 & HLA-A*02:01 & SLYNTIATL \\
\hline $1 \mathrm{~T} 21$ & 1 & HLA-A*02:01 & SLYNTVATL \\
\hline $1 \mathrm{~T} 22$ & 1 & HLA-A*02:01 & SLYNTVATL \\
\hline 1TVB & 1 & HLA-A*02:01 & ITDQVPFSV \\
\hline $1 \mathrm{TVH}$ & 1 & HLA-A*02:01 & IMDQVPFSV \\
\hline 2BNQ & 1 & HLA-A*02:01 & SLLMWITQV \\
\hline 2BNR & 1 & HLA-A*02:01 & SLLMWITQC \\
\hline $2 \mathrm{C} 7 \mathrm{U}$ & 1 & HLA-A*02:01 & SLFNTIAVL \\
\hline 2CLR & 1 & HLA-A*02:01 & MLLSVPLLLG \\
\hline 2F53 & 1 & HLA-A*02:01 & SLLMWITQC \\
\hline $2 \mathrm{~F} 54$ & 1 & HLA-A*02:01 & SLLMWITQC \\
\hline $2 \mathrm{GIT}$ & 1 & HLA-A*02:01 & LLFGKPVYV \\
\hline $2 \mathrm{GJ} 6$ & 1 & HLA-A*02:01 & LLFGKPVYV \\
\hline 2GT9 & 1 & HLA-A*02:01 & EAAGIGILTV \\
\hline 2GTW & 1 & HLA-A*02:01 & LAGIGILTV \\
\hline $2 \mathrm{GTZ}$ & 1 & HLA-A*02:01 & ALGIGILTV \\
\hline 2GUO & 1 & HLA-A*02:01 & AAGIGILTV \\
\hline 2P5E & 1 & HLA-A*02:01 & SLLMWITQC \\
\hline 2P5W & 1 & HLA-A*02:01 & SLLMWITQC \\
\hline 2PYE & 1 & HLA-A*02:01 & SLLMWITQC \\
\hline $2 \mathrm{~V} 2 \mathrm{~W}$ & 1 & HLA-A*02:01 & SLYNTVATL \\
\hline $2 \mathrm{~V} 2 \mathrm{X}$ & 1 & HLA-A*02:01 & SLFNTVATL \\
\hline 2VLJ & 1 & HLA-A*02:01 & GILGFVFTL \\
\hline 2VLK & 1 & HLA-A*02:01 & GILGFVFTL \\
\hline 2VLL & 1 & HLA-A*02:01 & GILGFVFTL \\
\hline 2VLR & 1 & HLA-A*02:01 & GILGFVFTL \\
\hline $2 \mathrm{X} 4 \mathrm{~N}$ & 1 & HLA-A*02:01 & KILGGVFXV \\
\hline $2 X 40$ & 1 & HLA-A*02:01 & KLTPLCVTL \\
\hline $2 \mathrm{X} 4 \mathrm{P}$ & 1 & HLA-A*02:01 & MILGGVFXV \\
\hline $2 X 4 Q$ & 1 & HLA-A*02:01 & MILGGVFXV \\
\hline $2 \mathrm{X} 4 \mathrm{R}$ & 1 & HLA-A*02:01 & NLVPMVATV \\
\hline $2 \mathrm{X} 4 \mathrm{~S}$ & 1 & HLA-A*02:01 & AMDSNTLEL \\
\hline $2 \mathrm{X} 4 \mathrm{~T}$ & 1 & HLA-A*02:01 & NLVPMVATV \\
\hline
\end{tabular}


O. Serçinoğlu ve P. Özbek / HLA Proteinlerinin GNM Metodu ile Dinamik Karakterizasyonu

\begin{tabular}{|c|c|c|c|c|}
\hline $2 \mathrm{X} 4 \mathrm{U}$ & 1 & HLA-A*02:01 & ILKEPVHGV & 2.10 \\
\hline $2 \times 70$ & 1 & HLA-A*02:01 & KILGGVFXV & 2.0 \\
\hline 3BGM & 1 & HLA-A*02:01 & RQASLSISV & \\
\hline 3ВН8 & 1 & HLA-A*02:01 & RQASIELPSM & \\
\hline 3ВН9 & 1 & HLA-A*02:01 & RTYSGPMNKV & \\
\hline 3ВНB & 1 & HLA-A*02:01 & KMDSFLDMQL & \\
\hline $3 \mathrm{D} 25$ & 1 & HLA-A*02:01 & VLHDDLLEA & \\
\hline 3D39 & 1 & HLA-A*02:01 & LLFGFPVYV & \\
\hline 3D3V & 1 & HLA-A*02:01 & LLFGFPVYV & \\
\hline $3 F Q N$ & 1 & HLA-A*02:01 & YLDSGIHSGA & \\
\hline $3 F Q R$ & 1 & HLA-A*02:01 & YLDSGIHSGA & 1. \\
\hline 3FQT & 1 & HLA-A*02:01 & GLLGSPVRA & \\
\hline $3 F Q U$ & 1 & HLA-A*02:01 & GLLGSPVRA & $1 . \varepsilon^{2}$ \\
\hline $3 \mathrm{FQW}$ & 1 & HLA-A*02:01 & RVASPTSGV & 1. \\
\hline $3 F Q X$ & 1 & HLA-A*02:01 & RVASPTSGV & \\
\hline 3FT2 & 1 & HLA-A*02:01 & VLRDDLLEA & \\
\hline 3FT3 & 1 & HLA-A*02:01 & VLHDDLLEA & \\
\hline 3FT4 & 1 & HLA-A*02:01 & VLRDDLLEA & 1. \\
\hline $3 \mathrm{GIV}$ & 1 & HLA-A*02:01 & SLFNTVATLY & 2.0 \\
\hline $3 \mathrm{GJF}$ & 1 & HLA-A*02:01 & SLLMWITQV & \\
\hline $3 G S O$ & 1 & HLA-A*02:01 & NLVPMVATV & 1.6 \\
\hline 3GSQ & 1 & HLA-A*02:01 & NLVPSVATV & \\
\hline 3GSR & 1 & HLA-A*02:01 & NLVPVVATV & 1. \\
\hline $3 \mathrm{GSU}$ & 1 & HLA-A*02:01 & NLVPTVATV & $1 . \varepsilon$ \\
\hline 3GSV & 1 & HLA-A*02:01 & NLVPQVATV & 1.9 \\
\hline 3GSW & 1 & HLA-A*02:01 & NLVPMVAAV & 1. \\
\hline $3 G S X$ & 1 & HLA-A*02:01 & NLVPMVAVV & \\
\hline 3H7B & 1 & HLA-A*02:01 & MLWGYLQYV & $1 . \varepsilon$ \\
\hline $3 \mathrm{H} 9 \mathrm{~S}$ & 1 & HLA-A*02:01 & MLWGYLQYV & 2. \\
\hline 3HAE & 1 & HLA-A*02:01 & SLLMWITQV & \\
\hline 3HG1 & 1 & HLA-A*02:01 & ELAGIGILTV & 3.0 \\
\hline 3HLA & 1 & HLA-A*02:01 & 0 & \\
\hline 3HPJ & 1 & HLA-A*02:01 & RMFPNAPYL & 2. \\
\hline $3 \mathrm{I} 6 \mathrm{G}$ & 1 & HLA-A*02:01 & GLMWLSYFV & \\
\hline $3 \mathrm{I} 6 \mathrm{~K}$ & 1 & HLA-A*02:01 & TLACFVLAAV & \\
\hline 3KLA & 1 & HLA-A*02:01 & SLLMWITQL & \\
\hline $3 \mathrm{MGO}$ & 1 & HLA-A*02:01 & RLYQNPTTYI & \\
\hline $3 \mathrm{MGT}$ & 1 & HLA-A*02:01 & KLYQNPTTYI & \\
\hline 3MR9 & 1 & HLA-A*02:01 & NLVPAVATV & \\
\hline
\end{tabular}


O. Serçinoğlu ve P. Özbek / HLA Proteinlerinin GNM Metodu ile Dinamik Karakterizasyonu

\begin{tabular}{|c|c|c|c|c|}
\hline 3MRB & 1 & HLA-A*02:01 & NLVPMVHTV & 1.40 \\
\hline 3MRC & 1 & HLA-A*02:01 & NLVPMCATV & 1.80 \\
\hline 3MRD & 1 & HLA-A*02:01 & NLVPMGATV & 1.70 \\
\hline 3MRE & 1 & HLA-A*02:01 & GLCTLVAML & 1.10 \\
\hline $3 \mathrm{MRF}$ & 1 & HLA-A*02:01 & GLCPLVAML & 2.30 \\
\hline 3MRG & 1 & HLA-A*02:01 & CINGVCWTV & 1.30 \\
\hline $3 \mathrm{MRH}$ & 1 & HLA-A*02:01 & CISGVCWTV & 2.40 \\
\hline 3MRI & 1 & HLA-A*02:01 & CINMWCWTV & 2.10 \\
\hline 3MRJ & 1 & HLA-A*02:01 & CINGMCWTV & 1.87 \\
\hline 3MRK & 1 & HLA-A*02:01 & PLFQVPEPV & 1.40 \\
\hline 3MRL & 1 & HLA-A*02:01 & CINGVVWTV & 2.41 \\
\hline 3MRM & 1 & HLA-A*02:01 & KLVALGINAV & 1.90 \\
\hline 3MRN & 1 & HLA-A*02:01 & LLFNILGGWV & 2.30 \\
\hline 3MRO & 1 & HLA-A*02:01 & ELAGWGILTV & 2.35 \\
\hline 3MRP & 1 & HLA-A*02:01 & ELAGLGINTV & \\
\hline 3MRQ & 1 & HLA-A*02:01 & ELAGLGINTV & 2.20 \\
\hline 3MRR & 1 & HLA-A*02:01 & LLAGIGTVPI & 1.60 \\
\hline 3MYJ & 1 & HLA-A*02:01 & YMFPNAPYL & 1.89 \\
\hline $303 \mathrm{~A}$ & 1 & HLA-A*02:01 & XLAXXLTV & 1.80 \\
\hline 303B & 1 & HLA-A*02:01 & ELAXXLTV & 1.90 \\
\hline 303D & 1 & HLA-A*02:01 & ELAXXLTV & 1.70 \\
\hline $303 E$ & 1 & HLA-A*02:01 & XLAXXLTV & \\
\hline 304L & 1 & HLA-A*02:01 & GLCTLVAML & 2.54 \\
\hline 3PWJ & 1 & HLA-A*02:01 & LLYGFVNYV & 1.70 \\
\hline 3PWL & 1 & HLA-A*02:01 & LGYGFVNYI & 1.65 \\
\hline $3 P W N$ & 1 & HLA-A*02:01 & LLYGFVNYI & 1.60 \\
\hline 3PWP & 1 & HLA-A*02:01 & LGYGFVNYI & 2.69 \\
\hline 3QDG & 1 & HLA-A*02:01 & ELAGIGILTV & 2.69 \\
\hline 3QDJ & 1 & HLA-A*02:01 & AAGIGILTV & 2.30 \\
\hline 3QDM & 1 & HLA-A*02:01 & ELAGIGILTV & 2.80 \\
\hline $3 Q E Q$ & 1 & HLA-A*02:01 & AAGIGILTV & 2.59 \\
\hline 3QFD & 1 & HLA-A*02:01 & AAGIGILTV & 1.68 \\
\hline $3 \mathrm{QFJ}$ & 1 & HLA-A*02:01 & LLFGFPVYV & 2.29 \\
\hline 3REW & 1 & HLA-A*02:01 & CLGGLLTMV & 1.90 \\
\hline 3Т02 & 1 & HLA-A*02:01 & LACFVLAAV & 2.60 \\
\hline 3UTQ & 1 & HLA-A*02:01 & ALWGPDPAAA & 1.67 \\
\hline $3 V 5 D$ & 1 & HLA-A*02:01 & KVAELVHFL & 2.00 \\
\hline $3 \mathrm{~V} 5 \mathrm{H}$ & 1 & HLA-A*02:01 & KVAEIVHFL & 1.63 \\
\hline $3 V 5 K$ & 1 & HLA-A*02:01 & KVAELVWFL & \\
\hline
\end{tabular}


O. Serçinoğlu ve P. Özbek / HLA Proteinlerinin GNM Metodu ile Dinamik Karakterizasyonu

\begin{tabular}{|c|c|c|c|c|}
\hline $4 \mathrm{E} 5 \mathrm{X}$ & 1 & HLA-A*02:01 & LLFGYPVYV & 1.95 \\
\hline 4EUP & 1 & HLA-A*02:01 & ALGIGILTV & \\
\hline 4EUQ & 1 & HLA-A*02:01 & EAAGIGILTV & \\
\hline $4 \mathrm{GKN}$ & 1 & HLA-A*02:01 & FATGIGIITV & \\
\hline 4GKS & 1 & HLA-A*02:01 & FLTGIGIITV & \\
\hline $4 \mathrm{I} 4 \mathrm{~W}$ & 1 & HLA-A*02:01 & ILAKFLHWL & \\
\hline $3 \mathrm{H} 9 \mathrm{H}$ & 1 & HLA-A*02:01 & MLWGYLQYV & \\
\hline 3IXA & 1 & HLA-A*02:01 & LLFGYPVYV & \\
\hline $2 \mathrm{AV7}$ & 1 & HLA-A*02:01 & LLFGYPVYV & \\
\hline $2 J 8 U$ & 1 & HLA-A*02:01 & ALWGFFPVL & \\
\hline $2 \mathrm{AV} 1$ & 1 & HLA-A*02:01 & LLFGYPVYV & \\
\hline 2UWE & 1 & HLA-A*02:01 & ALWGFFPVL & \\
\hline 2JCC & 1 & HLA-A*02:01 & ALWGFFPVL & \\
\hline $30 \times 8$ & 1 & HLA-A*02:03 & FLPSDFFPSV & \\
\hline $30 \times R$ & 1 & HLA-A*02:06 & FLPSDFFPSV & 1,7 \\
\hline $30 X S$ & 1 & HLA-A*02:07 & FLPSDFFPSV & \\
\hline $2 X P G$ & 1 & HLA-A*03:01 & KLIETYFSK & \\
\hline 3RL1 & 1 & HLA-A*03:01 & AIFQSSMTK & \\
\hline 3RL2 & 1 & HLA-A*03:01 & QVPLRPMTYK & 2.3 \\
\hline $1 Q 94$ & 1 & HLA-A*11:01 & AIFQSSMTK & \\
\hline $1 Q V 0$ & 1 & HLA-A*11:01 & QVPLRPMTYK & \\
\hline $1 X 7 Q$ & 1 & HLA-A*11:01 & КТFРРТЕРК & \\
\hline 2HN7 & 1 & HLA-A*11:01 & AIMPARFYPK & \\
\hline $2 \mathrm{BCK}$ & 1 & HLA-A*24:02 & VYGFVRACL & \\
\hline $3 \mathrm{I} 6 \mathrm{~L}$ & 1 & HLA-A*24:02 & QFKDNVILL & \\
\hline $3 N F N$ & 1 & HLA-A*24:02 & RYPLTFGWCF & \\
\hline 3QZW & 1 & HLA-A*24:02 & RYPLTFGWCF & \\
\hline $4 \mathrm{~F} 7 \mathrm{M}$ & 1 & HLA-A*24:02 & LYASPQLEGF & \\
\hline 4F7P & 1 & HLA-A*24:02 & FYRYGFVANF & \\
\hline 4 F7T & 1 & HLA-A*24:02 & RYGFVANF & \\
\hline $1 \mathrm{HSB}$ & 1 & HLA-A*68:01 & AVA & \\
\hline $1 \mathrm{TMC}$ & 1 & HLA-A*68:01 & EVAPPEYHRK & \\
\hline 2HLA & 1 & HLA-A*68:01 & 0 & \\
\hline 3VCL & 1 & HLA-B* 07:02 & RPHERNGFTVL & \\
\hline $1 \mathrm{AGB}$ & 1 & HLA-B*08:01 & GGRKKYKL & \\
\hline 1AGC & 1 & HLA-B*08:01 & GGKKKYQL & \\
\hline 1AGD & 1 & HLA-B*08:01 & GGKKKYKL & \\
\hline $1 \mathrm{AGE}$ & 1 & HLA-B*08:01 & GGKKKYRL & \\
\hline $1 \mathrm{AGF}$ & 1 & HLA-B*08:01 & GGKKRYKL & \\
\hline
\end{tabular}


O. Serçinoğlu ve P. Özbek / HLA Proteinlerinin GNM Metodu ile Dinamik Karakterizasyonu

\begin{tabular}{|c|c|c|c|c|}
\hline $1 \mathrm{M} 05$ & 1 & HLA-B*08:01 & FLRGRAYGL & 1.90 \\
\hline $1 \mathrm{MI} 5$ & 1 & HLA-B*08:01 & FLRGRAYGL & 2.5 \\
\hline $3 \mathrm{FFC}$ & 1 & HLA-B*08:01 & FLRGRAYGL & \\
\hline $3 \mathrm{SJV}$ & 1 & HLA-B*08:01 & FLRGRAYGL & \\
\hline 3SKM & 1 & HLA-B*08:01 & FLRGRAYVL & \\
\hline 3SPV & 1 & HLA-B*08:01 & RAKFKQLL & \\
\hline 3SKO & 1 & HLA-B* ${ }^{*}$ :01 & FLRGRAYGL & \\
\hline 3BXN & 1 & HLA-B*14:02 & IRAAPPPLF & \\
\hline 1XR8 & 1 & HLA-B*15:01 & LEKARGSTY & \\
\hline 1XR9 & 1 & HLA-B*15:01 & ILGPPGSVY & \\
\hline $3 \mathrm{C} 9 \mathrm{~N}$ & 1 & HLA-B*15:01 & VQQESSFVM & \\
\hline 1HSA & 1 & HLA-B*27:05 & ARAAAAAAA & \\
\hline 1JGE & 1 & HLA-B*27:05 & GRFAAAIAK & \\
\hline 10GT & 1 & HLA-B*27:05 & RRKWRRWHL & 1. \\
\hline $1 U X S$ & 1 & HLA-B*27:05 & RRRWRRLTV & \\
\hline $1 \mathrm{~W} 0 \mathrm{~V}$ & 1 & HLA-B*27:05 & RRLPIFSRL & \\
\hline $2 A 83$ & 1 & HLA-B*27:05 & RRRWHRWRL & \\
\hline 2BSR & 1 & HLA-B*27:05 & RRIYDLIEL & \\
\hline 2BSS & 1 & HLA-B*27:05 & KRWIILGLNK & 2.0 \\
\hline 2BST & 1 & HLA-B*27:05 & SRYWAIRTR & \\
\hline $3 B 6 S$ & 1 & HLA-B*27:05 & RRKWRRWHL & $1 . \varepsilon$ \\
\hline $3 \mathrm{BP} 4$ & 1 & HLA-B*27:05 & IRAAPPPLF & \\
\hline 3DTX & 1 & HLA-B*27:05 & RRKWRRWHL & 2. \\
\hline 3LV3 & 1 & HLA-B*27:05 & SRRWRRWNR & 1. \\
\hline $4 \mathrm{G} 8 \mathrm{G}$ & 1 & HLA-B*27:05 & KRWIILGLNK & 2,4 \\
\hline 4G8I & 1 & HLA-B*27:05 & KRWIIMGLNK & 1,6 \\
\hline 4G9D & 1 & HLA-B*27:05 & KRWIILGLNK & 1,6 \\
\hline $4 \mathrm{G} 9 \mathrm{~F}$ & 1 & HLA-B*27:05 & KRWIIMGLNK & 1,9 \\
\hline 1JGD & 1 & HLA-B*27:09 & RRLLRGHNQY & \\
\hline $1 \mathrm{~K} 5 \mathrm{~N}$ & 1 & HLA-B*27:09 & GRFAAAIAK & \\
\hline $10 F 2$ & 1 & HLA-B*27:09 & RRKWRRWHL & \\
\hline 1UXW & 1 & HLA-B*27:09 & RRRWRRLTV & \\
\hline 1W0W & 1 & HLA-B*27:09 & RRLPIFSRL & 2 \\
\hline 3B3I & 1 & HLA-B*27:09 & RRKWRRWHL & \\
\hline 3BP7 & 1 & HLA-B*27:09 & IRAAPPPLF & \\
\hline $3 \mathrm{CZF}$ & 1 & HLA-B*27:09 & RRRWHRWRL & \\
\hline 3D18 & 1 & HLA-B*27:09 & RRRWRRLTL & \\
\hline $3 \mathrm{HCV}$ & 1 & HLA-B*27:09 & RRKWRRWHL & \\
\hline $1 \mathrm{~A} 1 \mathrm{~N}$ & 1 & HLA-B*35:01 & VPLRPMTY & \\
\hline
\end{tabular}


O. Serçinoğlu ve P. Özbek / HLA Proteinlerinin GNM Metodu ile Dinamik Karakterizasyonu

\begin{tabular}{|c|c|c|c|c|}
\hline $1 \mathrm{~A} 9 \mathrm{~B}$ & 1 & HLA-B*35:01 & LPPLDITPY & 3.20 \\
\hline $1 \mathrm{~A} 9 \mathrm{E}$ & 1 & HLA-B*35:01 & LPPLDITPY & 2,5 \\
\hline 1CG9 & 1 & HLA-B*35:01 & LPPLDITPY & \\
\hline 1XH3 & 1 & HLA-B*35:01 & LPAVVGLSPGEQEY & 1.4 \\
\hline $1 \mathrm{ZHK}$ & 1 & HLA-B*35:01 & LPEPLPQGQLTAY & \\
\hline $1 Z S D$ & 1 & HLA-B*35:01 & EPLPQGQLTAY & \\
\hline $2 A X G$ & 1 & HLA-B*35:01 & APQPAPENAY & \\
\hline $2 \mathrm{CIK}$ & 1 & HLA-B*35:01 & KPIVVLHGY & \\
\hline $2 \mathrm{FYY}$ & 1 & HLA-B*35:01 & HPVGEADYFEY & \\
\hline $2 \mathrm{H} 6 \mathrm{P}$ & 1 & HLA-B*35:01 & KPIVVLHGY & \\
\hline $2 \mathrm{NX} 5$ & 1 & HLA-B*35:01 & EPLPQGQLTAY & 2.7 \\
\hline $3 \mathrm{LKN}$ & 1 & HLA-B*35:01 & LPFERATIM & \\
\hline 3LKO & 1 & HLA-B*35:01 & LPFDRTTIM & 1.8 \\
\hline 3LKP & 1 & HLA-B*35:01 & LPFDKSTIM & \\
\hline 3LKQ & 1 & HLA-B*35:01 & LPFDKTTIM & \\
\hline 3LKR & 1 & HLA-B*35:01 & LPFERATVM & 2.0 \\
\hline 3LKS & 1 & HLA-B*35:01 & LPFEKSTVM & \\
\hline $3 \mathrm{MV7}$ & 1 & HLA-B*35:01 & HPVGEADYFEY & 2.0 \\
\hline 3MV8 & 1 & HLA-B*35:01 & HPVGEADYFEY & \\
\hline 3MV9 & 1 & HLA-B*35:01 & HPVGEADYFEY & \\
\hline $1 \mathrm{ZHL}$ & 1 & HLA-B*35:08 & LPEPLPQGQLTAY & 1.5 \\
\hline $2 \mathrm{AK} 4$ & 1 & HLA-B*35:08 & LPEPLPQGQLTAY & \\
\hline $2 \mathrm{AXF}$ & 1 & HLA-B*35:08 & APQPAPENAY & $1 . \varepsilon$ \\
\hline $2 \mathrm{FZ3}$ & 1 & HLA-B*35:08 & HPVGEADYFEY & \\
\hline 2NW3 & 1 & HLA-B*35:08 & EPLPQGQLTAY & 1. \\
\hline 3BW9 & 1 & HLA-B*35:08 & CPSQEPMSIYVY & 1.7 \\
\hline 3BWA & 1 & HLA-B*35:08 & FPTKDVAL & \\
\hline $3 \mathrm{VFS}$ & 1 & HLA-B*35:08 & LPEPAPQGQLTAY & 1.8 \\
\hline $3 V F T$ & 1 & HLA-B*35:08 & LPEPLAQGQLTAY & \\
\hline $3 \mathrm{VFU}$ & 1 & HLA-B*35:08 & LPEPLPAGQLTAY & 1. \\
\hline $3 \mathrm{VFV}$ & 1 & HLA-B*35:08 & LPEPLPQGALTAY & \\
\hline 3VFW & 1 & HLA-B*35:08 & LPEPLPQGQATAY & \\
\hline 4JRX & 1 & HLA-B*35:08 & LPEPLPQGQLTAY & 2,3 \\
\hline $4 J R Y$ & 1 & HLA-B*35:08 & LPEPLPQGQLTAY & 2,8 \\
\hline $3 \mathrm{KWW}$ & 1 & HLA-B*35:08 & LPEPLPQGQLTAY & \\
\hline $3 \mathrm{KXF}$ & 1 & HLA-B*35:08 & LPEPLPQGQLTAY & \\
\hline 3LN4 & 1 & HLA-B*41:03 & AEMYGSVTEHPSPSPL & \\
\hline 3LN5 & 1 & HLA-B*41:04 & HEEAVSVDRVL & \\
\hline $1 \mathrm{M} 60$ & 1 & HLA-B*44:02 & EEFGRAFSF & \\
\hline
\end{tabular}


O. Serçinoğlu ve P. Özbek / HLA Proteinlerinin GNM Metodu ile Dinamik Karakterizasyonu

\begin{tabular}{|c|c|c|c|c|}
\hline 3DX6 & 1 & HLA-B*44:02 & EENLLDFVRF & 1.70 \\
\hline 3KPL & 1 & HLA-B*44:02 & EEYLQAFTY & 1. \\
\hline $3 \mathrm{KPM}$ & 1 & HLA-B*44:02 & EEYLKAWTF & \\
\hline 3L3D & 1 & HLA-B*44:02 & EEAGRAFSF & 1.8 \\
\hline 3L3G & 1 & HLA-B*44:02 & EEFGAAFSF & \\
\hline 3L3I & 1 & HLA-B*44:02 & EEFGRAASF & \\
\hline 3L3J & 1 & HLA-B*44:02 & EEAGAAFSF & 2.40 \\
\hline $3 \mathrm{~L} 3 \mathrm{~K}$ & 1 & HLA-B*44:02 & EEFGAAASF & \\
\hline $1 \mathrm{~N} 2 \mathrm{R}$ & 1 & HLA-B*44:03 & EEFGRAFSF & 1.7 \\
\hline 1SYS & 1 & HLA-B*44:03 & EEPTVIKKY & \\
\hline 3DX7 & 1 & HLA-B*44:03 & EENLLDFVRF & 1.6 \\
\hline $3 \mathrm{KPN}$ & 1 & HLA-B*44:03 & EEYLQAFTY & \\
\hline $3 \mathrm{KPO}$ & 1 & HLA-B*44:03 & EEYLKAWTF & 2. \\
\hline 1SYV & 1 & HLA-B*44:05 & EEFGRAFSF & 1.7 \\
\hline 3DX8 & 1 & HLA-B*44:05 & EENLLDFVRF & \\
\hline 3DXA & 1 & HLA-B*44:05 & EENLLDFVRF & 3.5 \\
\hline 3КРP & 1 & HLA-B*44:05 & EEYLQAFTY & \\
\hline $3 \mathrm{KPQ}$ & 1 & HLA-B*44:05 & EEYLKAWTF & 1.8 \\
\hline $3 \mathrm{KPR}$ & 1 & HLA-B*44:05 & EEYLKAWTF & 2.6 \\
\hline $3 \mathrm{KPS}$ & 1 & HLA-B*44:05 & EEYLQAFTY & 2.7 \\
\hline $1 \mathrm{E} 27$ & 1 & HLA-B*51:01 & LPPVVAKEI & 2.2 \\
\hline $1 \mathrm{E} 28$ & 1 & HLA-B*51:01 & TAFTIPSI & 3.0 \\
\hline $3 W 39$ & 1 & HLA-B*52:01 & TAFTIPSI & 3,1 \\
\hline $1 \mathrm{~A} 1 \mathrm{M}$ & 1 & HLA-B*53:01 & TPYDINQML & 2.3 \\
\hline $1 \mathrm{~A} 10$ & 1 & HLA-B*53:01 & KPIVQYDNF & 2.3 \\
\hline 2RFX & 1 & HLA-B*57:01 & LSSPVTKSF & 2.5 \\
\hline 2YPK & 1 & HLA-B*57:01 & KAFSPEVIPMF & \\
\hline 3UPR & 1 & HLA-B*57:01 & HSITYLLPV & 2.0 \\
\hline 3VH8 & 1 & HLA-B*57:01 & LSSPVTKSF & 1.8 \\
\hline 3VRI & 1 & HLA-B*57:01 & RVAQLEQVYI & 1.6 \\
\hline 3VRJ & 1 & HLA-B*57:01 & LTTKLTNTNI & 1.9 \\
\hline $2 \mathrm{BVO}$ & 1 & HLA-B*57:03 & KAFSPEVIPMF & 1.6 \\
\hline 2BVP & 1 & HLA-B*57:03 & ISPRTLDAW & 1.3 \\
\hline 2BVQ & 1 & HLA-B*57:03 & KAFSPEVIP & \\
\hline $2 \mathrm{HJK}$ & 1 & HLA-B*57:03 & KGFNPEVIPMF & \\
\hline $2 \mathrm{HJL}$ & 1 & HLA-B*57:03 & KAFNPEIIPMF & \\
\hline 2YPL & 1 & HLA-B*57:03 & KAFSPEVIPMF & 2.4 \\
\hline $1 \mathrm{EFX}$ & 1 & HLA-C*03:04 & GAVDPLLAL & \\
\hline 1IM9 & 1 & HLA-C* $04: 01$ & QYDDAVYKL & \\
\hline
\end{tabular}


O. Serçinoğlu ve P. Özbek / HLA Proteinlerinin GNM Metodu ile Dinamik Karakterizasyonu

\begin{tabular}{|c|c|c|c|c|}
\hline 1QQD & 1 & HLA-C*04:01 & QYDDAVYKL & 2.70 \\
\hline 3LQZ & 2 & $\begin{array}{c}\text { HLA- } \\
\text { DPA1*01:03/DP } \\
\text { B1*02:01 }\end{array}$ & RKFHYLPFLPST & 3.25 \\
\hline 4D8P & 2 & HLA-DQ & PQPEQPEQPFPQP & 3.05 \\
\hline 1JK8 & 2 & HLA-DQ8 & SHLVEALYLVCGERG & 2.40 \\
\hline 2NNA & 2 & HLA-DQ8 & SGEGSFQPSQENP & 2.10 \\
\hline 1UVQ & 2 & $\begin{array}{c}\text { HLA- } \\
\text { DQA1*01:02/D } \\
\text { QB1*06:02 }\end{array}$ & MNLPSTKVSWAAV & 1.80 \\
\hline 4GG6 & 2 & $\begin{array}{c}\text { HLA- } \\
\text { DQA1*03:01/D } \\
\text { QB1*03:02 }\end{array}$ & QQYPSGQGSFQPSQQNPQ & 3.20 \\
\hline $1 \mathrm{~S} 9 \mathrm{~V}$ & 2 & $\begin{array}{c}\text { HLA- } \\
\text { DQA1*05:01/D } \\
\text { QB1*02:01 }\end{array}$ & LQPFPQPQLPY & 2.22 \\
\hline $1 \mathrm{FYT}$ & 2 & HLA-DR1 & PKYVKQNTLKLAT & 2.60 \\
\hline 1JWM & 2 & HLA-DR1 & PKYVKQNTLKLAT & 2.70 \\
\hline 1JWS & 2 & HLA-DR1 & PKYVKQNTLKLAT & 2.60 \\
\hline 1JWU & 2 & HLA-DR1 & PKYVKQNTLKLAT & 2.30 \\
\hline 1KG0 & 2 & HLA-DR1 & PKYVKQNTLKLAT & 2.65 \\
\hline $1 \mathrm{KLG}$ & 2 & HLA-DR1 & GELIGILNAAKVPAD & 2.40 \\
\hline $1 \mathrm{KLU}$ & 2 & HLA-DR1 & GELIGTLNAAKVPAD & 1.93 \\
\hline 1L05 & 2 & HLA-DR1 & PKYVKQNTLKLAT & 3.20 \\
\hline 1PYW & 2 & HLA-DR1 & FVKQNAAAL & 2.10 \\
\hline 1R5I & 2 & HLA-DR1 & PKYVKQNTLKLAT & 2.60 \\
\hline 1SEB & 2 & HLA-DR1 & AAAAAAAAAAAAA & 2.70 \\
\hline 1T5W & 2 & HLA-DR1 & AAYSDQATPLLLSPR & 2.40 \\
\hline 1T5X & 2 & HLA-DR1 & AAYSDQATPLLLSPR & 2.50 \\
\hline 2ICW & 2 & HLA-DR1 & PKYVKQNTLKLAT & 2.41 \\
\hline 20JE & 2 & HLA-DR1 & PKYVKQNTLKLAT & 3.00 \\
\hline 3PDO & 2 & HLA-DR1 & $\begin{array}{c}\text { KPVSKMRMATPLLMQAL } \\
\text { PM }\end{array}$ & 1.95 \\
\hline 3PGC & 2 & HLA-DR1 & KMRMATPLLMQALPM & 2.66 \\
\hline 3PGD & 2 & HLA-DR1 & KMRMATPLLMQALPM & 2.72 \\
\hline $3 S 4 S$ & 2 & HLA-DR1 & PKYVKQNTLKLAT & 2.40 \\
\hline 3S5L & 2 & HLA-DR1 & PKYVKQNTLKLAT & 2.10 \\
\hline 4AEN & 2 & HLA-DR1 & MKMRMATPLLMQALPM & 2.20 \\
\hline $4 \mathrm{AH} 2$ & 2 & HLA-DR1 & MKMRMATPLLMQAL & 2.36 \\
\hline 1BX2 & 2 & HLA-DR2 & ENPVVHFFKNIVTPR & 2.60 \\
\hline $1 \mathrm{~A} 6 \mathrm{~A}$ & 2 & HLA-DR3 & $\begin{array}{l}\text { LPKPPKPVSKMRMATPLL } \\
\text { MQALPM }\end{array}$ & 2.75 \\
\hline $1 \mathrm{MUJ}$ & 2 & HLA-DR3 & $\begin{array}{l}\text { GSHSRGLPKPPKPVSKMR } \\
\text { MATPLLMQALPMGSGSGS }\end{array}$ & 2.15 \\
\hline \multirow[t]{2}{*}{$1 \mathrm{~J} 8 \mathrm{H}$} & 2 & HLA-DR4 & PKYVKQNTLKLAT & 2.40 \\
\hline & & & 396 & \\
\hline
\end{tabular}


O. Serçinoğlu ve P. Özbek / HLA Proteinlerinin GNM Metodu ile Dinamik Karakterizasyonu

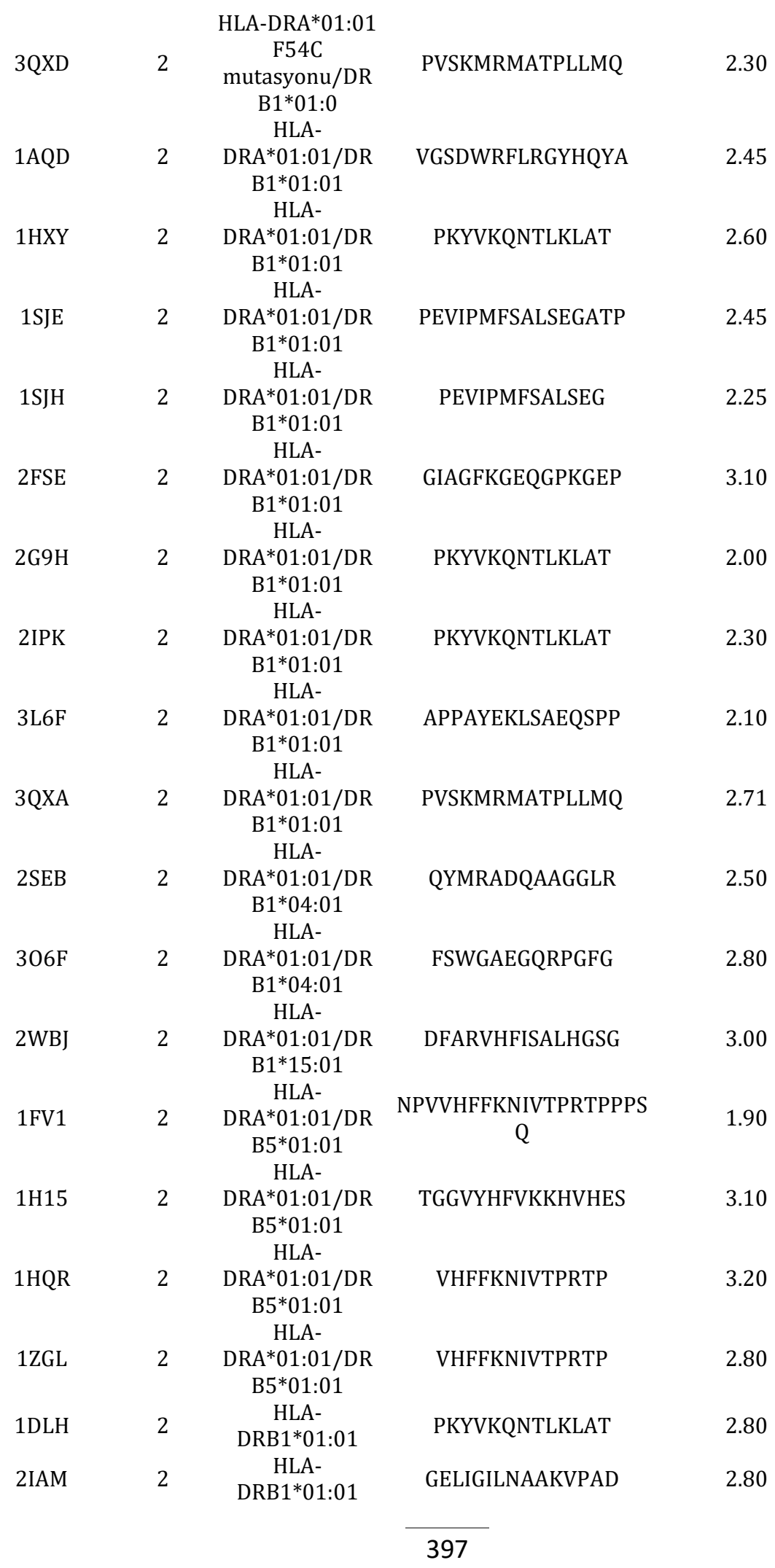


O. Serçinoğlu ve P. Özbek / HLA Proteinlerinin GNM Metodu ile Dinamik Karakterizasyonu

\begin{tabular}{|c|c|c|c|c|}
\hline 2IAN & 2 & $\begin{array}{c}\text { HLA- } \\
\text { DRB1*01:01 }\end{array}$ & GELIGTLNAAKVPAD & 2.80 \\
\hline 4FQX & 2 & $\begin{array}{c}\text { HLA- } \\
\text { DRB1*01:01 }\end{array}$ & GKQNCLKLATK & 2.60 \\
\hline $4 \mathrm{GBX}$ & 2 & $\begin{array}{c}\text { HLA- } \\
\text { DRB1*01:01 }\end{array}$ & GKQNCLKLATK & 3.00 \\
\hline 1D5M & 2 & $\begin{array}{c}\text { HLA- } \\
\text { DRB1*04:01 }\end{array}$ & XRAMXSX & 2.00 \\
\hline 1D5X & 2 & $\begin{array}{c}\text { HLA- } \\
\text { DRB1*04:01 }\end{array}$ & XRXXX & 2.45 \\
\hline $1 \mathrm{D} 5 \mathrm{Z}$ & 2 & $\begin{array}{c}\text { HLA- } \\
\text { DRB1*04:01 }\end{array}$ & XRAXSX & 2.00 \\
\hline 1D6E & 2 & $\begin{array}{c}\text { HLA- } \\
\text { DRB1*04:01 }\end{array}$ & XRXMASX & 2.45 \\
\hline 1YMM & 2 & $\begin{array}{c}\text { HLA- } \\
\text { DRB1*15:01 }\end{array}$ & ENPVVHFFKNIVTPR & 3.50 \\
\hline 2Q6W & 2 & $\begin{array}{c}\text { HLA- } \\
\text { DRB3*01:01 }\end{array}$ & AWRSDEALPLGS & 2.25 \\
\hline $3 \mathrm{C} 5 \mathrm{~J}$ & 2 & $\begin{array}{c}\text { HLA- } \\
\text { DRB3*03:01 }\end{array}$ & QVIILNHPGQISA & 1.80 \\
\hline 4H1L & 2 & $\begin{array}{c}\text { HLA- } \\
\text { DRB3*03:01 }\end{array}$ & HIRCNIPKRI & 3.30 \\
\hline $1 \mathrm{MHE}$ & 1 & HLA-E*01:01 & VMAPRTVLL & 2.85 \\
\hline $2 \mathrm{ESV}$ & 1 & HLA-E*01:01 & VMAPRTLIL & 2.60 \\
\hline 3BZE & 1 & HLA-E*01:01 & VMAPRTLFL & 2.50 \\
\hline $3 \mathrm{BZF}$ & 1 & HLA-E*01:01 & VMAPRALLL & 2.50 \\
\hline $3 C D G$ & 1 & HLA-E*01:01 & VMAPRTLFL & 3.40 \\
\hline $3 \mathrm{CII}$ & 1 & HLA-E*01:01 & VMAPRTLFL & 4.41 \\
\hline $1 \mathrm{KPR}$ & 1 & HLA-E*01:03 & VMAPRTVLL & 2.80 \\
\hline $1 \mathrm{KTL}$ & 1 & HLA-E*01:03 & VTAPRTLLL & 3.10 \\
\hline 2DYP & 1 & HLA-G*01:01 & RIIPRHLQL & 2.50 \\
\hline 1YDP & 1 & HLA-G*01:01 & RIIPRHLQL & 1.90 \\
\hline 2D31 & 1 & HLA-G*01:01 & RIIPRHLQL & 3.20 \\
\hline $3 \mathrm{KYN}$ & 1 & HLA-G*01:01 & KGPPAALTL & 2.40 \\
\hline $3 \mathrm{KYO}$ & 1 & HLA-G*01:01 & KLPAQFYIL & 1.70 \\
\hline
\end{tabular}


O. Serçinoğlu ve P. Özbek / HLA Proteinlerinin GNM Metodu ile Dinamik Karakterizasyonu

Ek B. Veri Setinde Bulunan Sinıf I Yapıları Arasındaki Alfa-Karbon RMSD Dağılımı

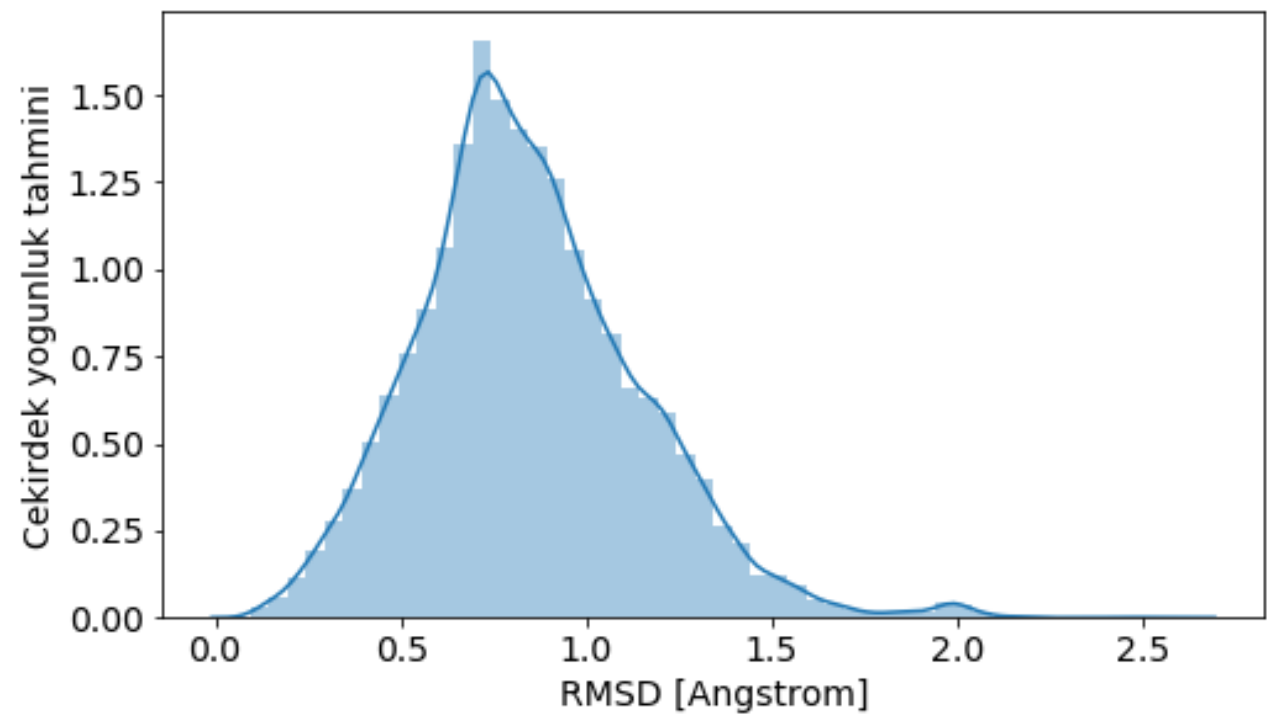

